conditions. A method free from some of these objections has now been devised. It depends on the catalytic combustion of traces of methyl bromide in air on a glowing platinum wire and the determination of the bromine liberated by the coloration of a test paper. The paper is wetted with a pale yellow solution of fluorescein, more or less of which is changed to red eosin according to the amount of methyl bromide decomposed. The apparatus, which is portable, consists of a vertical glass tube towards the bottom of which is mounted a platinum spiral which can be caused to glow by the passage of a current from a small 4-volt cell. The test paper, which is perforated in the middle, is fastened over the top end of the tube. When the current is switched on, a stream of air passes over the spiral and up the tube, which acts as a chimney, and the eosin, which appears as a ring on the paper surrounded by a white border, can readily be matched against standard disks.

By using different periods of testing and different colour standards, determinations of traces of methyl bromide can readily be made over a wide range of concentrations covering those which are of toxicological importance.

A fuller account of this method is being published elsewhere.

Department of Zoology and

O. F. Lubatis. Applied Entomology,

Imperial College of Science and Technology. Nov. 24.

\section{Extraction of Phospholipids in Salmon Roe}

IN the course of investigations on salmon roe globulin, the interesting observation was made that the phospholipids in the roe are so strongly held by the proteins that non-polar or semi-polar solvents with a low boiling point (pentane, light petroleum, ethyl ether) do not extract any phospholipid at all from salmon roe, which was previously dried at a temperature below $40^{\circ} \mathrm{C}$., although the oil can be completely extracted by such solvents.

It was found by Hoppe-Seyler ${ }^{1}$ and others that egg yolk lecithin and phospholipids from other sources are partly extractable with light petroleum or ethyl ether, but that their complete removal could only be accomplished by using a polar solvent such as methyl or ethyl alcohol. In no case, however, did he obtain a complete separation of the oil from the phospholipids. Only milk phospholipids have been reported to differ in this respect. Osborne and Wakeman $^{2,3}$ found that the phospholipids of milk precipitated together with the proteins were not extracted at all by ethyl ether, although a subsequent treatment with alcohol removed a considerable amount. These authors stated that the non-proteincontaining fraction of milk contains phosphorus. Such findings are understandable for milk, which contains only about $27 \mathrm{mgm}$. of phospholipids per litre, but it was surprising to find no phospholipids in the solvent-extracted oil from salmon roe, while a subsequent extraction with alcohol removed on the average 6 per cent phospholipids. This is about 2,000 times the amount found in milk.

Experiments with salmon roe were as follows : fresh salmon roe was dried at $30^{\circ} \mathrm{C}$. in the stream of air from a fan. The dried material was ground to 20-30 mesh and extracted with pentane in a
Soxhlet apparatus. The oil obtained by this method contained the pigments; but no phosphorus, as shown by ashing and testing with ammonium molybdate.

The pentane-extracted roe was reground to $50-80$ mesh, and thoroughly extracted with methanol in the same Soxhlet apparatus. The phospholipids so ob. tained had a reddish-brown, waxy appearance and a characteristic odour. They were free from oil. The ash content was about 10 per cent, the phosphorus content between $2 \cdot 9$ and 3.4 per cent, the moisture content 3-5 per cent.

On the average, the roe from sockeye salmon (Oncorhynchus nerka) yielded by the above method 12.5 per cent oil and $6 \cdot 2$ per cent phospholipids.

Laboratory,

The Canadian Fishing Company, Ltd.,

Vancouver, British Columbia.

${ }^{1}$ Hoppe-Seyler, T., Hoppe-Seyler Med. Chem. Unters., 8, 392 (1867). Osborne, T. B., and Wakeman, J. Biol. Chem., 21, 539 (1915). ${ }^{3}$ Osborne, T. B., and Wakeman, J. Biol. Chem., 23, 1 (1916).

\section{Apparent Clearing of the Sky at Dusk}

Clouds may disappear by evaporation of the droplets, a purely physical effect, but they may also vanish to the eye, though in fact they remain. It is generally accepted that the eye can distinguish between brightnesses down to the limit of 2 per cent difference, which may be termed the discrimination factor. The best papers on this factor and its variation with intensity are those of Nutting ${ }^{1}$ and Hecht ${ }^{2}$. In average daylight for good eyes, the factor may be as low as 1 per cent, increasing for very bright light to about 6 per cent, and for much-reduced illumination rising steeply to more than 60 per cent; but the value 2 per cent holds approximately over a wide range of daylight.

This variation gives the explanation of 'the moonlight effect', since in shadows the general illumination is so low that the discrimination factor rises beyond the difference between adjacent objects which in daylight were distinguishable. Precisely the same explanation holds good in the sky, where differences recognizable in daylight disappear in reduced light in which discrimination may require a 5,10 or 20 per cent difference. For example, Hewson ${ }^{3}$ has calculated that radiation from a source at $25^{\circ}$ zenith distance is reduced by $6 \cdot 6$ per cent in intensity in passing through 20 metres of cloud having droplets of $10 \mu$ diameter and a droplet water content of $0.1 \mathrm{gm}$. per cubic metre, as in high cloud. The loss is due to reflexion, absorption being negligible for daylight. Against a dark sky such a cloud is therefore visible until the discrimination factor approaches 7 per cent, which occurs when sky brightness is about 0.01 milli. lambert, shortly before the end of civil twilight. A similar cloud $200 \mathrm{~m}$. thick reflects approximately 40 per cent, and ceases to be discriminated when the brightness is reduced to 0.0003 millilamberts, namely, about the end of nautical twilight.

There is also another factor tending to lessen the visibility of clouds at dusk. A cloud appears white against the blue sky because the latter scatters light predominantly blue and the former reflects or scatters white light from the sun. But when the sun is well down, clouds are illuminated only by scattered sunlight and starlight. They thus approach more closely to blue-the spectral region to which our dark- 